Article

\title{
Variation and Prediction Methods of the Explosion Characteristic Parameters of Coal Dust/Gas Mixtures
}

\author{
Yingquan $\mathrm{Qi}^{1,2}$, Xiangyang Gan ${ }^{1,2}$, Zhong $\mathrm{Li}^{1,2}, \mathrm{Lu} \mathrm{Li}^{1,2}$, Yan Wang ${ }^{1,2} \mathbb{C}$ and Wentao $\mathrm{Ji}^{1,2, *}$ \\ 1 State Key Laboratory Cultivation Bases for Gas Geology and Gas Control, \\ College of Safety Science and Engineering, Henan Polytechnic University, Jiaozuo 454000, China; \\ nuoweihaidao@hotmail.com (Y.Q.); gxyoung@aliyun.com (X.G.); 13523712362@163.com (Z.L.); \\ 18035843044@163.com (L.L.); yanwang@hpu.edu.cn (Y.W.) \\ 2 The Collaboration Innovation Center of Coal Safety Production of Henan Province, Henan Polytechnic \\ University, Jiaozuo 454000, China \\ * Correspondence: jiwentao@hpu.edu.cn
}

Citation: Qi, Y.; Gan, X.; Li, Z.; Li, L.; Wang, Y.; Ji, W. Variation and Prediction Methods of the Explosion Characteristic Parameters of Coal Dust/Gas Mixtures. Energies 2021, 14, 264. https://doi.org/10.3390/ en14020264

Received: 25 November 2020 Accepted: 4 January 2021 Published: 6 January 2021

Publisher's Note: MDPI stays neutral with regard to jurisdictional clai$\mathrm{ms}$ in published maps and institutional affiliations.

Copyright: (C) 2021 by the authors. Licensee MDPI, Basel, Switzerland. This article is an open access article distributed under the terms and conditions of the Creative Commons Attribution (CC BY) license (https:// creativecommons.org/licenses/by/ $4.0 /)$.

\begin{abstract}
In order to investigate the change law of the explosion characteristic parameters of hybrid mixture of coal dust and gas, and then establish an effective prediction method of these parameters, the maximum explosion pressure, explosion index, and lower explosion limit of coal dust and gas mixtures were measured in a standard $20 \mathrm{~L}$ spherical explosion system. Four different kinds of hybrid mixture were selected in this study and they are composed of coal dust with different components and gas respectively. According to the measured results, the change law of the explosion characteristic parameters of hybrid mixture of coal dust and gas was analyzed, and the prediction method of these parameters was discussed. The results show that the addition of gas to a coal dust cloud can obviously increase its maximum explosion pressure and explosion index and notably reduce its minimum explosion concentration. On increasing the gas equivalent ratio, the maximum explosion pressure of coal dust and gas mixture increases linearly and the explosion index increases quadratically, while the decrease curve of the lower explosion limit is nonlinear. Based on these change laws, the methods for predicting the maximum explosion pressure and the explosion index of hybrid mixture of coal dust and gas were established respectively. The applicability of the existing methods for predicting the lower explosion limit of hybrid mixture to coal dust and gas mixture was demonstrated.
\end{abstract}

Keywords: gas; coal dust; hybrid explosion; characteristic parameters; prediction model

\section{Introduction}

Coal is China's basic energy source. It has always provided important support for the rapid economic development of China. However, explosion accidents that have occurred in coal mines have often caused serious casualties and huge property losses, hindering the development of the coal industry. The research shows that most of the explosion accidents in mining areas are often caused by a hybrid mixture of coal dust and gas. Even if the accidents are identified as coal dust explosions or gas explosions, the explosion process usually involves both gas and coal dust [1]. Therefore, research on the explosion characteristics of the hybrid mixture of coal dust and gas is of great significance for preventing coal mine explosion disasters and ensuring coal mine production safety.

Scholars have conducted a lot of research on the explosion characteristics of coal dust and gas mixtures. Research by Bartknech [2] showed that adding a small amount of methane to coal dust can significantly increase its explosion pressure and pressure rise rate. Song et al. [3] used a modified $20 \mathrm{~L}$ spherical explosion container to study the explosion characteristics of coal dust and gas mixtures. According to the experimental results, they clarified the relationship between the optimum explosion concentration, maximum explosion pressure, and maximum rate of explosion pressure rise of coal dust and gas mixture and the initial pressure of the system. Kundu et al. [4] added different concentrations 
of coal dust to methane with a concentration of $9.5 \%$. They found that the addition of any concentration of coal dust to methane with the optimum explosion concentration will reduce the methane's explosion pressure. Zhao et al. [5] studied the explosion characteristics of six hybrid mixtures composed of bituminous coal, anthracite, methane, hydrogen, and carbon monoxide. They concluded that different gases have different effects on the explosion parameters of different coal dust. Many scholars have also studied the influence of igniter energy [6], medium concentration [7], coal dust composition [8], particle size [9], oxygen concentration [10], moisture content [11], turbulence intensity [12], etc. on the explosion characteristics of coal dust and gas mixtures. Besides, researchers have also made some achievements in the flame combustion and propagation of hybrid mixture of coal dust and gas. Bi et al. [13] studied the flame propagation characteristics of hybrid mixture of coal dust and gas in different initial conditions using a $1.2 \mathrm{~m}$ long vertical tube. They indicated that the flame propagation speed of hybrid explosion is significantly higher than that of gas explosion. When the gas concentration is closer to the stoichiometric ratio, the flame propagation speed of the hybrid explosion is faster. Jing et al. [14] measured the hybrid coal dust/gas explosion pressure in a semi-enclosed vertical space by changing the concentration and particle size of the coal dust and found that the maximum explosion pressure in the explosion cavity increased to a significantly higher level than the pipeline propagation. Guo [15] constructed a system to test the hybrid coal dust/gas explosion propagation law and analyzed the influence of the volatile and gas content of the coal dust on the hybrid explosion law. Niu [16] studied the influence of moisture content of coal dust on the propagation law of hybrid explosions of coal dust and gas and found that when the moisture content exceeds $20.28 \%$, the hybrid mixture of coal dust and gas will not explode.

The above research clarifies the macroscopic explosion characteristics of coal dust and gas mixtures. These researches are of great significance for guiding coal mine production safety. However, the safety protection design of coal mine is often based on specific values of the explosive characteristic parameter. But it is limited to the dynamic change of the coal dust and gas concentration ratio, experimenters cannot measure the hybrid explosion characteristic parameters for all ratios. Therefore, it is extremely important to construct a prediction method for predicting the explosion characteristic parameters of coal dust and gas mixtures. For this purpose, Cashdollar et al. [17] established a model to predict the lower explosion limit of hybrid mixture of coal dust and gas under the assumption that the hybrid coal dust/gas explosion is a homogeneous reaction process. But this model is only suitable for coal dust and gas with a similar flame temperature. Bartknecht modified Cashdollar's model and proposed a more applicable Bartknecht model. Jiang considered the influence of the initial turbulence and constructed a model by correlating the explosion index to predict the lower explosion limit of the hybrid mixture. Britton proposed a semi-empirical formula for predicting the minimum ignition energy of hybrid mixtures by analyzing a large amount of experimental data on the minimum ignition energy of the hybrid coal dust/gas mixture. Khalili put forward a new model for prediction of the hybrid mixture minimum ignition energy based on the introduction of the diameter of the critical ignition kernel. Yu et al. [18] established a prediction model for the maximum explosion pressure and explosion index of hybrid mixture by studying the explosion characteristics of a hybrid mixture composed of methane, ethylene, lycopodium, polyethylene, etc.

The above models can provide some reference and help for the prevention and control of hybrid explosion disasters. However, all of these models are semi-empirical formulas, which have limitations in practical use [19-21]. Moreover, the explosion mechanism of hybrid mixture of coal dust and gas is still unclear and the unique method for predicting the explosion characteristic parameters of coal dust and gas mixtures has not yet been established. Therefore, it is very important to verify the applicability of the existing models for the prediction of the explosion characteristic parameters of hybrid mixture of coal dust and gas, and then modify the existing model or establish a new prediction model to ensure the safe production of coal mines. 
In the present paper, four kinds of coal dust with different components were selected. The hybrid explosion experiments were carried out in a standard $20 \mathrm{~L}$ spherical container. According to the experimental results, the change law of the maximum explosion pressure, lower explosion limit, and explosion index of hybrid mixture of coal dust and gas were analyzed. The applicability of the existing models for predicting the explosion characteristic parameters of hybrid mixture to coal dust and gas mixtures was analyzed. Based on the analysis results, suggestions for modifying the model are proposed, to establish a more accurate model for predicting the explosion characteristic parameters of the hybrid mixture of coal dust and gas.

\section{Experimental Equipment and Materials}

\subsection{Experimental Equipment}

The schematic diagram of the $20 \mathrm{~L}$ spherical container is shown in Figure 1. The experimental system includes an explosive container, a control box, and a data acquisition collection system. The control box includes a programmable controller, an electric spark generator, a touch screen, a pressure collection terminal board, etc. The touch screen and the computer are connected via a local area network. The explosive container is stainless steel double-layer structure. The interlayer can be filled with water to keep the temperature in the container constant. There is an observation window on the container, through which the flame of the ignition and explosion can be observed. The bottom of the container is equipped with a gas-powder two-phase valve that can pass the gas-dust mixture. The valve is opened and closed pneumatically to ensure control of the opening and closing speed. The movement of the pneumatic piston is controlled by two solenoid valves. Reflective nozzles are installed at the bottom of the container to evenly disperse the dust in the explosive container. A piezoelectric pressure sensor with a range and frequency of $0-2 \mathrm{MPa}$ and $20 \mathrm{kHz}$ is installed on the container wall. The sensor can measure the dynamic pressure of the powder injection air intake and explosion process. The pressure change process in the container is converted into electrical signals by pressure sensors and transmitters, which are collected by the data acquisition system and stored in the computer. The chemical igniter's energy is $10 \mathrm{~kJ}$. The ignition delay time is $60 \mathrm{~ms}$.
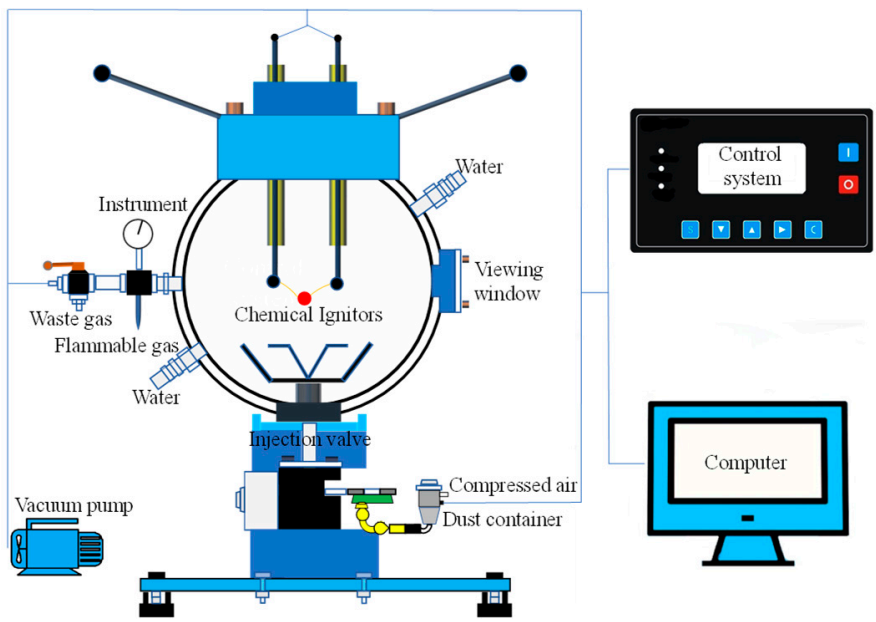

Figure 1. $20 \mathrm{~L}$ spherical explosive system.

Table 1 shows the uncertainties parameters and measurement ranges in this study. The estimation of the uncertainty is based on all quantifiable errors, according to the number of measurements and process control parameters. For the lower explosion limit, maximum explosion pressure, and the explosion index of hybrid mixture, the total measurement error could be obtained by combining the individual relative error as shown below. It can be seen that the individual relative error is $3.8 \%$, which is low enough to ensure measurement accuracy. 
Table 1. Uncertainties, parameters, and measurement ranges.

\begin{tabular}{ccccc}
\hline Parameters & Symbol & Maximum Error & Symbol & Value of Measurement \\
\hline mass measurement & $\Delta \mathrm{m}$ & $0.05 \mathrm{~g}$ & $\mathrm{~m}$ & $15 \mathrm{~g}$ \\
gas concentration & $\Delta \mathrm{C}_{\mathrm{g}}$ & $0.1 \mathrm{vol} \%$ & $\mathrm{C}_{\mathrm{g}}$ & $10 \%$ \\
dust dispersion pressure & $\Delta \mathrm{P}_{\mathrm{d}}$ & $0.001 \mathrm{MPa}$ & $\mathrm{P}_{\mathrm{d}}$ & $2 \mathrm{MPa}$ \\
pressure sensor reading & $\Delta \mathrm{P}_{\mathrm{r}}$ & $0.001 \mathrm{MPa}$ & $\mathrm{P}_{\mathrm{r}}$ & $0.5 \mathrm{MPa}$ \\
\hline
\end{tabular}

Individual relative error $=\frac{\Delta m}{m}+\frac{\Delta C g}{C g}+\frac{\Delta P d}{P d}+\frac{\Delta P r}{P r}=3.8 \%$

The experiment complied with the EN 14034 [22] standard. There follows an outline of the experimental course employed for coal dust, gas, and hybrid mixture of coal dust and gas:

1. For hybrid mixture of coal dust and gas: in order to accomplish the hybrid mixture explosion experiments, after the coal dust was first placed in the $0.6 \mathrm{~L}$ container the premixed gas/air mixture at $2 \mathrm{MPa}$ pressure was added using the partial pressure method. The coal dust was then dispersed through a rebound nozzle into the vacuum chamber at -0.6 bar via the premixed gas/air mixture.

2. For coal dust: when conducting the coal dust explosion experiments, the coal dust was first placed in the $0.6 \mathrm{~L}$ dust container, followed by the addition of the compressed air at $2 \mathrm{Mpa}$ pressure. The coal dust was then dispersed into the vacuum chamber at -0.6 bar by the compressed air.

3. For gas: when conducting the gas explosion experiments, the premixed gas/air mixture was prepared at $2 \mathrm{Mpa}$ pressure in the $0.6 \mathrm{~L}$ dust container via the partial pressure method, with the mixture then injected into the vacuum chamber at -0.6 bar without coal dust.

By using the methods described above, the explosion parameters of coal dust, gas, and coal dust/gas mixtures were obtained under the same initial pressure, temperature, turbulent, and ignition conditions, thus providing a feasible way to analyze the change law of the explosion parameters of coal dust and gas mixtures $[23,24]$. The initial pressure was the atmospheric pressure of $0.101 \mathrm{MPa}$. The initial temperature was $20^{\circ} \mathrm{C}$ which was controlled by the constant temperature water in the interlayer. The initial turbulent is controlled by the ignition delay time. The delay time in this study was $60 \mathrm{~ms}$ which was in accordance with EN 14034. The explosion is ignited by a $10 \mathrm{~kJ}$ chemical igniter which was also in accordance with EN 14034. Because the volume of the explosion container is $20 \mathrm{~L}$, it has been proven that this volume is big enough to ignore the wall effect. Therefore, the explosion container can be thought of as an adiabatic container. In order to ensure the repeatability of the experimental results, each experiment in this study was repeated three times. The average value of the results of three experiments was taken as the analytical data.

\subsection{Materials}

In order to systematically reflect the change law of the explosion characteristic parameters of hybrid mixture of coal dust and gas, this experiment selects 4 kinds of coal dust with different volatile contents as the research object. According to the principle of similar particle sizes and different volatile contents, they are divided into two groups $\mathrm{A}$ and $\mathrm{B}$. The four samples were named A1, A2, B1, and B2. The average diameters (D50) of A1 and A2 are 21.3 and $19.7 \mu \mathrm{m}$, respectively. The volatile components of A1 and A2 are $2.25 \%$ and $25.01 \%$, respectively. The average diameters (D50) of B1 and B2 are 36.5 and $35.3 \mu \mathrm{m}$, respectively. Their volatile components are $13.9 \%$ and $30.33 \%$, respectively. The intelligent particle size analyzer used for measuring the particle size distribution characteristics of the four samples is a Mastersizer 3000, which meets the ISO13320:2009 international standard. Figure 2 shows the volume distribution of the four coal dust particle sizes indicated by D10, D50, and D90. Before the experiment, the four samples were dried in a vacuum drying oven at $60^{\circ}$ for $24 \mathrm{~h}$. The proximate analysis of the four samples was done using a 5 E-MAG6700 analyzer and the results are shown in Table 2. In group A, the volatile and 
moisture contents of A1 are lower than A2, but the ash and fixed carbon contents are higher than A2. In group B, the volatile content of B1 is lower than B2, but the ash, fixed carbon, and moisture contents are higher than B2.
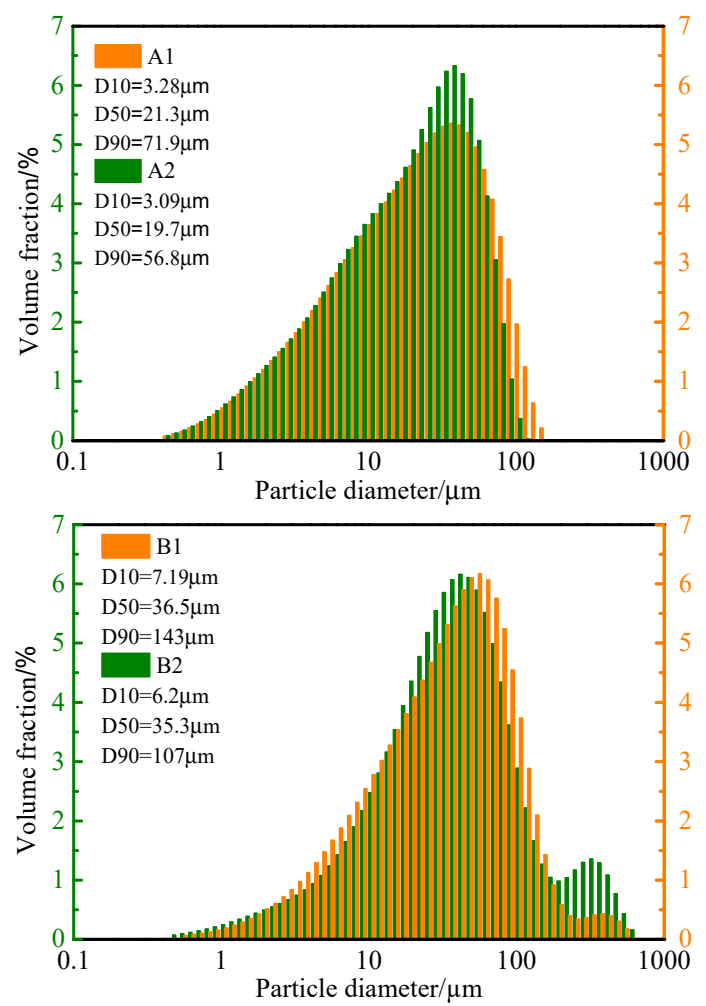

Figure 2. Four kinds of coal dust particle size distribution.

Table 2. Proximate analysis of four kinds of coal dust.

\begin{tabular}{ccccc}
\hline $\begin{array}{c}\text { Dust } \\
\text { Sample }\end{array}$ & $\begin{array}{c}\text { Fixed Carbon } \\
\text { Content }\end{array}$ & $\begin{array}{c}\text { Volatile } \\
\text { Content }\end{array}$ & $\begin{array}{c}\text { Moisture } \\
\text { Content }\end{array}$ & $\begin{array}{c}\text { Ash } \\
\text { Content }\end{array}$ \\
\hline A1 & 60.58 & 2.25 & 0.43 & 36.74 \\
A2 & 51.44 & 25.01 & 9.73 & 13.82 \\
B1 & 61 & 13.9 & 4.5 & 20.6 \\
B2 & 56.94 & 30.33 & 3.88 & 8.85 \\
\hline
\end{tabular}

\section{Experimental Results and Discussion}

3.1. Analysis of Maximum Explosion Pressure and Explosion Index Variation Law of Hybrid Mixture of Coal Dust and Gas

As shown in Figure 3, by measuring the explosion pressure and the rate of explosion pressure rise of coal dust of different concentrations under different gas concentration conditions, the change law of the maximum explosion pressure and explosion index of the hybrid mixture of coal dust and gas was obtained [18]. It can be seen from Figure 3 that for the four different hybrid mixtures, the maximum explosion pressure and explosion index both increase with the increase of gas concentration. While the corresponding optimum coal dust explosion concentration gradually decreases with the increase of gas concentration. The results were also reported in the study by Dufaud [25], Guo [15], Addai [26], and Song [27]. When the gas concentration increases to the optimum explosion concentration of $10 \%$, the maximum explosion pressure and explosion index of the four hybrid mixtures all reach the peak. Simultaneously, the corresponding optimum explosion concentration of coal dust decreases to $0 \mathrm{~g} / \mathrm{m}^{3}$, indicating that the peak values of the maximum explosion pressure and explosion index of the hybrid mixture are equal to those of $10 \%$ gas. It shows that adding any concentration of coal dust to $10 \%$ gas will result in a 
reduction in the maximum explosion pressure and explosion index of the gas. This can be attributed to the fact that under the condition of the optimum gas explosion concentration, the gas in the explosion process of the hybrid system will preferentially react with oxygen, while the solid coal dust mainly acts as "inert" particles to absorb heat. Therefore, it can be inferred that at any gas concentration, the maximum explosion pressure and explosion index of the hybrid mixture of coal dust and gas are lower than single-phase gas but higher than single-phase coal dust. That is to say the explosion intensity of the gas, coal dust, and the hybrid mixture satisfy the following relationship: coal dust < hybrid mixture < gas. This result is in accordance with that reported by Kundu [4], Ji [23], Yu [24], Sanchirico [28], and Garcia-Agreda [29].
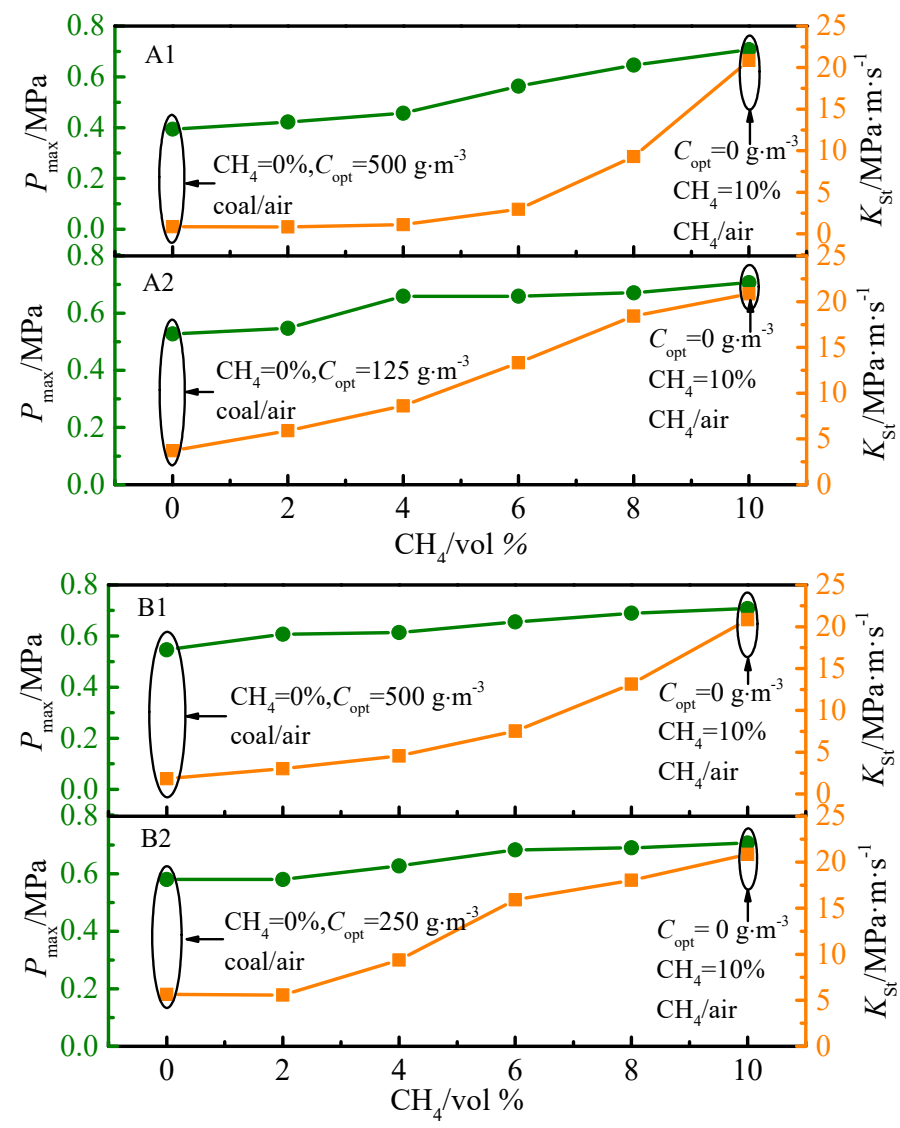

Figure 3. Diagram of maximum explosion pressure and exponential change of hybrid mixture of coal dust and gas.

On further analyzing the growth trends of the maximum explosion pressure and explosion index of the four different hybrid mixtures, it can be observed that the increase of the explosion index is significantly higher than the maximum explosion pressures, indicating that the gas has a more significant impact on the explosion index of coal dust. The similar conclusion can also be found in research of Bartknecht [2,30], Sanchirico [28], Garcia-Agreda [29], Pinho [31], Denkecit [32] and Mohammed [33]. This is because the explosion pressure of the explosion medium is mainly controlled by the heat of combustion, and the explosion index is controlled by the combustion rate. After adding a certain concentration of gas to the coal dust, part of the combustion heat of the hybrid mixture will come from gas combustion. However, the volume and the oxygen content of the explosion container is limited. The addition of gas only leads to the transformation of the combustion heat source, without forming an effective accumulation of the combustion medium content, so the maximum explosion pressure increase is limited. However, the addition of gas will induce the coal dust explosion to transform from heterogeneous combustion to 
homogeneous combustion, then leading to a rapid increase in the combustion rate, so the explosion index increases significantly.

\subsection{Analysis of the Change Law of the Lower Explosion Limit of Hybrid Mixture of Coal Dust and Gas}

As shown in Figure 4, the minimum explosion concentration of coal dust under different gas concentration conditions was measured, and the change curve of the lower explosion limit of coal dust and gas mixture was obtained. It can be seen from Figure 4 that for the four different coal dusts, the minimum explosion concentration decreases due to the addition of gas, and further decreases with the increase of the gas concentration. When the gas concentration increases to $4 \%$, the minimum explosion concentrations of the four kinds of coal dust reduce to $0 \mathrm{~g} / \mathrm{m}^{3}$. This is because the lower explosion limit of gas measured in this study is $4 \%$. That is to say, $4 \%$ of the gas can maintain the continuous propagation of the explosion flame of the system. In addition, the trend line of the lower explosion limit of the hybrid mixture divides the plane coordinate system into two zones, namely the upper explosive zone and the lower non-explosive zone. Taking any point in the explosion zone, the corresponding concentration of coal dust and gas can still explode after mixing, indicating that coal dust below its minimum explosion concentration and gas below its lower explosion limit will still be explosive after mixing [4].
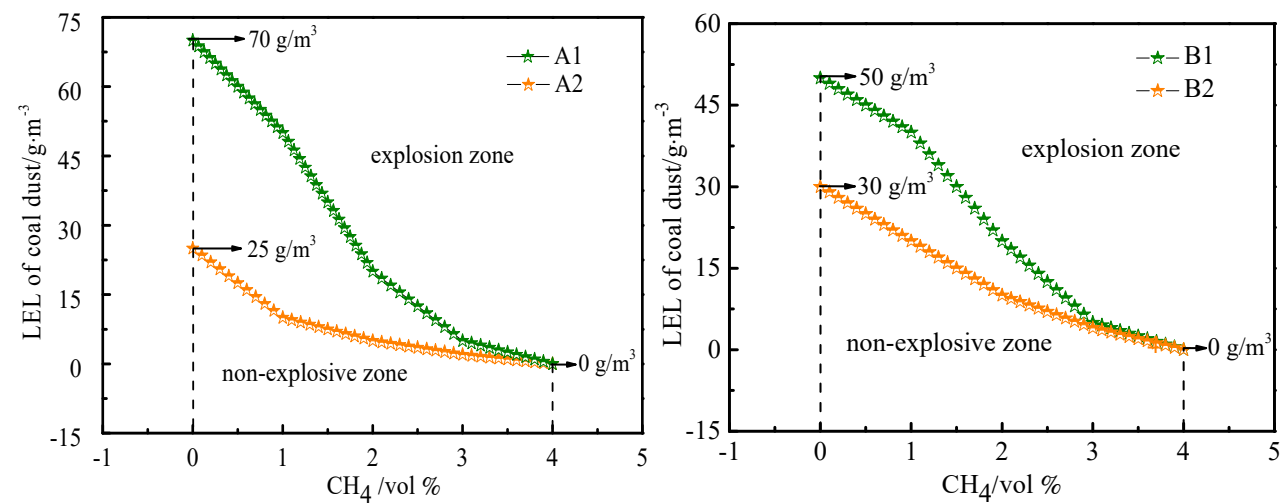

Figure 4. The minimum explosion concentration of coal dust varying with methane concentration.

The effects of gas on the minimum explosion pressure of different coal dust were further analyzed. Using the decreasing amplitude $\varphi$ of the minimum explosion concentration of coal dust caused by gas as the ordinate, and the gas concentration $y$ as the abscissa, the comparison chart of the different influences of gas on the minimum explosion concentration of different coal dusts is obtained, as shown in Figure 5. It is shown that compared with B1 and B2, the minimum explosive concentration of A1 and B1 has a greater decrease amplitude under the same concentration of gas. Because the volatile content of A1 and B1 is lower than that of A2 and B2, it can be inferred that the gas has a greater impact on the minimum explosion concentration of low-volatile coal dust. This is because the lower the volatile content of the coal dust, the lower the pyrolysis combustible gas content, which leads to a higher amount of coal dust required to pyrolyze enough combustible gas to maintain the combustion. Therefore, when the same concentration of gas is added, the minimum explosive concentration of low-volatile coal dust will be lower. However, with an increase of the gas concentration, the difference of the decreasing amplitude $\varphi$ between different coal dusts gradually decreases. It is due to that the difference of the influence of gas on the minimum explosion concentration of coal dust between different coal dusts decreases. This is because when the gas concentration gradually increases, the concentration of coal dust required for the explosion of the hybrid system gradually decreases, and the leading role of the gas increases. 


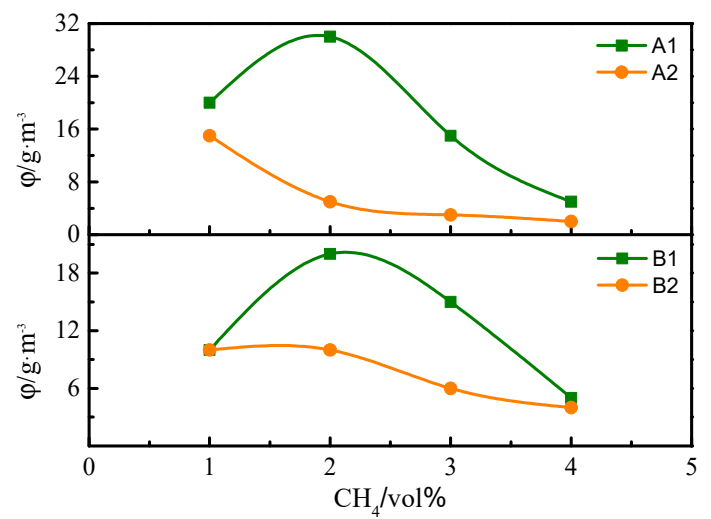

Figure 5. Decreasing amplitude of the minimum explosion concentration of coal dust varying with methane concentration.

3.3. Methods for Predicting Maximum Explosion Pressure and Explosion Index of Hybrid Mxiture of Coal Dust and Gas

In terms of the prediction of the maximum explosion pressure and explosion index of the hybrid mixture, studies on the explosion characteristics of four hybrid mixtures of polyethylene/methane, polyethylene/ethylene, lycopodium/methane, and lycopodium/ethylene show that the maximum explosion pressure and explosion index of the hybrid mixture are lower than single-phase combustible gas but higher than single-phase dust. The maximum explosion pressure increases linearly and the explosion index increases quadratically with the increase of the combustible gas equivalent ratio [18]. Based on this, the prediction models of the maximum explosion pressure and explosion index of the hybrid mixture were established, as shown in Equations (1) and (2):

$$
\begin{gathered}
P_{\max }^{H}=P_{\text {max }}^{S t}+\left(P_{\max }^{G}-P_{\max }^{S t}\right) \bullet \phi \\
K_{H}=K_{S t}+\left(K_{G}-K_{S t}\right) \bullet \phi^{2}
\end{gathered}
$$

where $P_{\max }^{H}$ is the maximum explosion overpressure of hybrid mixture (MPa), $P_{\max }^{S t}$ indicates the maximum explosion overpressure of dust $(\mathrm{MPa}), P_{\max }^{G}$ represents the maximum explosion overpressure of gas $(\mathrm{MPa}), K_{H}$ is the explosion index of hybrid mixture $(\mathrm{m} \cdot \mathrm{MPa} / \mathrm{s})$, $K_{S t}$ indicates the explosion index of dust $(\mathrm{m} \cdot \mathrm{MPa} / \mathrm{s}), K_{G}$ represents the explosion index of gas $(\mathrm{m} \cdot \mathrm{MPa} / \mathrm{s}), \Phi$ is the gas equivalent ratio in the hybrid mixture.

Figures 6 and 7 show the variation of the maximum explosion pressure and explosion index of the four hybrid mixtures of coal dust and gas selected in this paper with the gas equivalent ratio. It can be seen that the maximum explosion pressure of the four hybrid mixtures of coal dust and gas also increases linearly with the increase of the gas equivalent ratio and the explosion index increases quadratically. Therefore, Equations (1) and (2) have a certain applicability to the four hybrid mixtures of coal dust and gas selected in this paper. The verification results are shown in Figures 8 and 9.

It can be seen from Figure 8 that the maximum prediction error of the maximum explosion pressure of the two kinds of coal dust in group A is $0.06 \mathrm{MPa}$, and the maximum prediction error of the maximum explosion pressure of the two kinds of coal dust in group $B$ is 0.027 and $0.029 \mathrm{MPa}$, respectively. It is shown that the prediction results are in good agreement with the experimental results, and the relative error is small. From Figure 9, it can be seen that the maximum prediction errors of the explosion index of the two kinds of coal dust in group A are 3.44 and $5.11 \mathrm{~m} \cdot \mathrm{MPa} / \mathrm{s}$, respectively, and the maximum prediction errors of the explosion index of the two kinds of coal dust in group B are 3.37 and $4.79 \mathrm{~m} \cdot \mathrm{MPa} / \mathrm{s}$, respectively. In general, Equations (1) and (2) have good applicability to the hybrid mixture of coal dust and gas, with relatively small errors, and can be used to predict the maximum explosion pressure and explosion index of the hybrid mixture of coal dust and gas. 


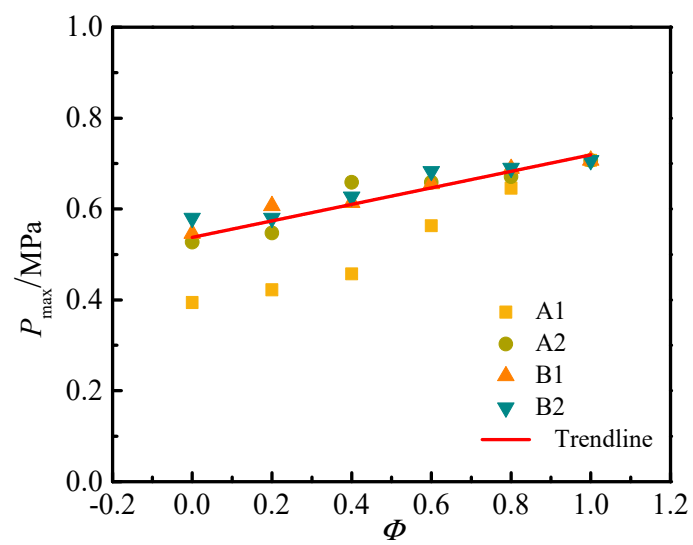

Figure 6. The maximum explosive pressure $P_{\max }$ of coal dust and gas mixtures changing with the gas equivalent ratio.

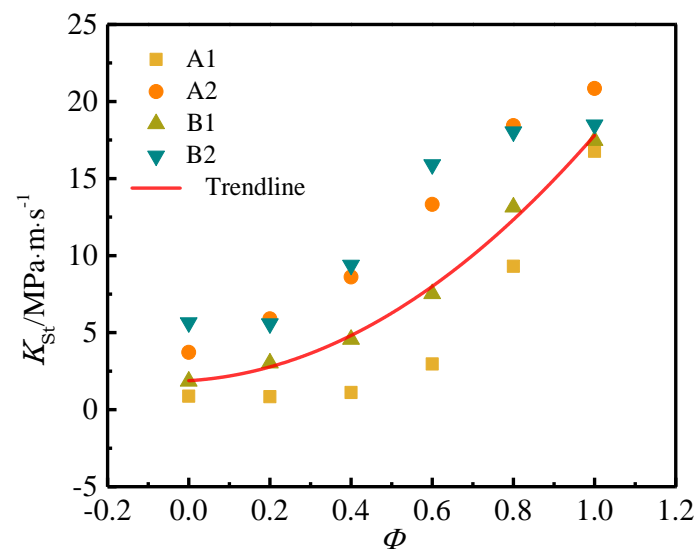

Figure 7. The explosion index $K_{\mathrm{St}}$ of coal dust and gas mixtures changing with the gas equivalent ratio.
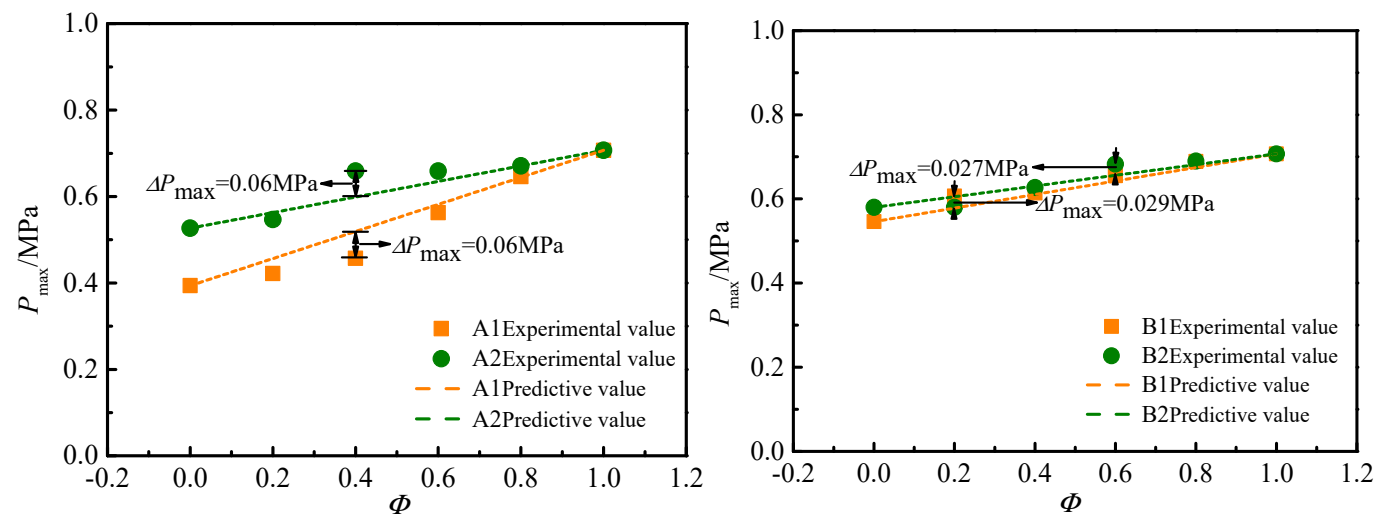

Figure 8. Comparison diagram of maximum explosion pressure prediction model and experimental results for hybrid mixtures. 

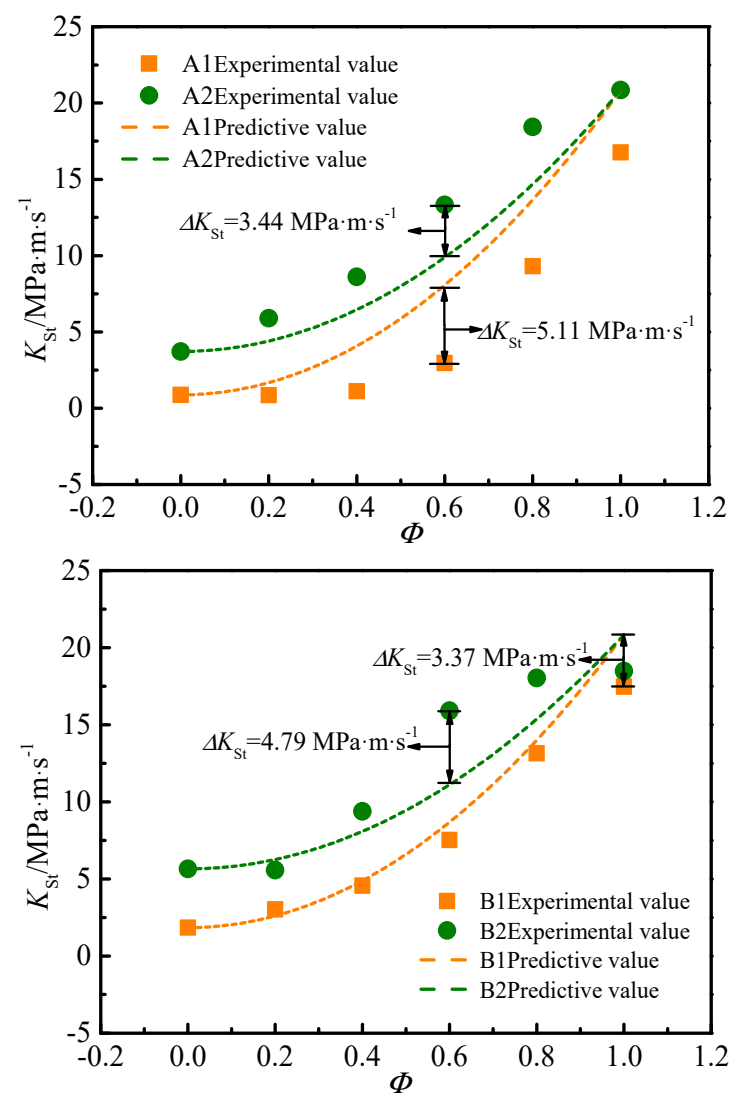

Figure 9. Comparison diagram of explosion index prediction model and experimental results for hybrid mixtures.

\subsection{Prediction Method of Lower Explosion Limit of Hybrid Mixture Coal Dust and Gas}

In terms of predicting the lower explosion limit of hybrid mixtures, the current common prediction models are:

Le Chatelier [17] model

$$
\frac{c}{M E C}+\frac{y}{L E L}=1
$$

Bartknecht [2] model

$$
\frac{c}{M E C}=\left(\frac{y}{L E L}-1\right)^{2}
$$

Jiang [34] model

$$
\frac{c}{M E C}=\left(\frac{y}{L E L}-1\right)^{(1.12 \pm 0.03) \frac{K_{S t}}{K_{G}}}
$$

where $c$ is the dust concentration $\left(\mathrm{g} / \mathrm{m}^{3}\right), y$ is the gas concentration (vol\%), MEC indicates the minimum explosion concentration of dust $\left(\mathrm{g} / \mathrm{m}^{3}\right)$, and LEL represents the lower explosion limit of gas (vol\%).

In order to verify the applicability of the above models, we take the ratio of the coal dust concentration to the minimum explosion concentration of the coal dust c/MEC as the ordinate, and the ratio of the gas concentration to the lower explosion limit of gas explosion y/LEL as the abscissa to obtain experimental measurement results and model prediction results in the comparison chart, as shown in Figure 10. As shown in Figure 10, for group A, the lower explosion limits of the two kinds of coal dust and gas mixtures are in the non-explosive zone of the Jiang model and the Le Chatelier model, indicating that the prediction results are dangerous, and the prediction error increases further with an increase of the gas concentration. The Bartknecht model has a certain applicability to coal dust in group A. When y/LEL is less than 0.5 , the measured value deviates slightly from the predicted value. But when $\mathrm{y} / \mathrm{LEL}$ is greater than 0.5 , the predicted value is 
basically consistent with the experimentally measured value, and the prediction accuracy is relatively high. For group B, the lower explosion limits of the two kinds of coal dust and gas mixtures are also in the non-explosive zone of the Jiang model and the Le Chatelier model, indicating the prediction results are dangerous, and the prediction error increases further with increase of the gas concentration. The predicted values of the Bartknecht model are all lower than the experimental measured values, indicating the predicted results are safe and have a certain applicability, and the prediction accuracy gradually increases with the increase of $y / L E L$.
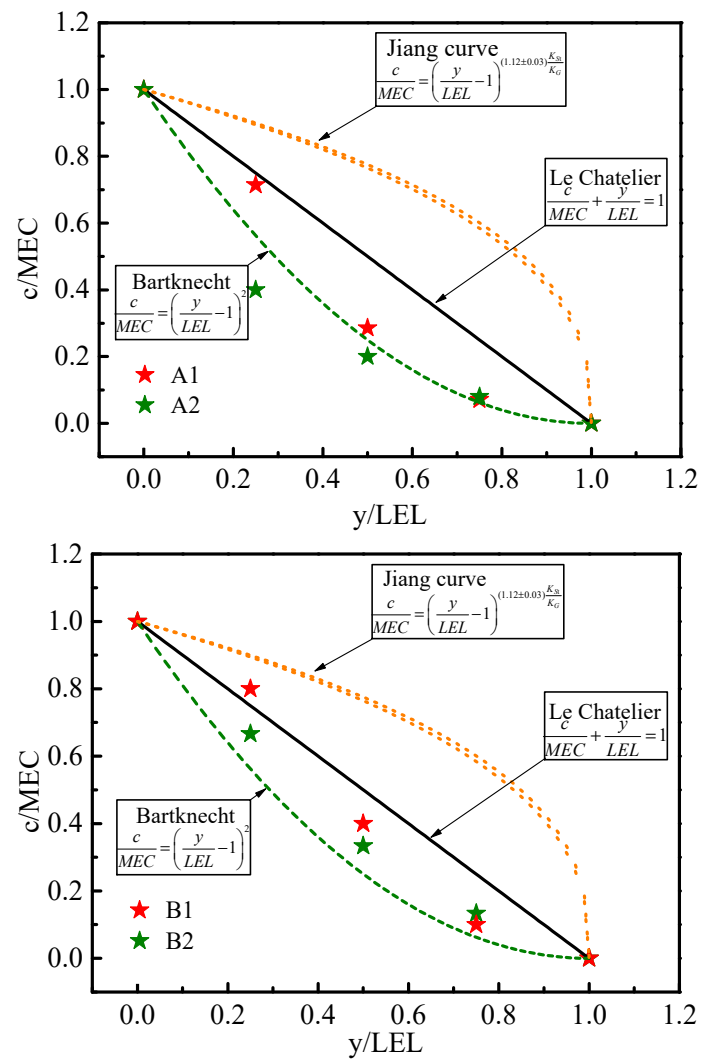

Figure 10. Comparison diagram of lower explosion limit prediction model and experimental results for hybrid mixtures.

Generally speaking, in the prediction of the lower explosion limit of hybrid mixture of coal dust and gas, the prediction results of the Jiang model and the Le Chatelier model are dangerous and are not applicable. The prediction results of the Bartknecht model are safer. Therefore, the Bartknecht model has a certain applicability to the hybrid mixture of coal dust and gas and is more suitable for the hybrid mixture containing low volatile coal dust.

\section{Conclusions}

In this paper, four different kinds of hybrid mixtures of coal dust and gas were selected, and their explosion characteristic parameters were measured in a standard $20 \mathrm{~L}$ spherical explosion system. According to the experimental results, the change law of the maximum explosion pressure, the explosion index, and the lower explosion limit of the hybrid mixture of coal dust and gas are clarified and three models used for predicting the maximum explosion pressure, the explosion index and the lower explosion limit of the hybrid mixture of coal dust and gas respectively were proposed, some conclusions can be summarized as follows:

(1) The addition of gas has a more obvious effect on the maximum explosion pressure and explosion index of coal dust with low volatile content. After the addition of gas, the increase in the explosion of coal dust is more significant than that in the maximum 
explosion pressure, indicating that the effect of gas on the explosion index of coal dust is more obvious.

(2) As the gas equivalent ratio in the hybrid mixture of coal dust and gas increases, the maximum explosion pressure of the hybrid mixture increases linearly, and the explosion index increases quadratically. However, at any gas concentration, the maximum explosion pressure and explosion index of coal dust and gas mixtures are lower than single-phase gas but higher than single-phase coal dust.

(3) The addition of gas can lead to a significant reduction in the lower explosion limit of the coal dust, and the reduction is affected by the volatile content of the coal dust. The lower the volatile content of the coal dust, the greater the reduction.

(4) Methods were established for predicting the maximum explosion pressure, explosion index, and lower explosion limit of coal dust and gas mixtures. The prediction results obtained by the maximum explosion pressure and explosion index prediction methods have relatively small errors and are suitable for a hybrid mixture of coal dust and gas. The Bartknecht model has a certain applicability to the hybrid mixture of coal dust and gas and is more suitable for the hybrid mixture containing low volatile coal dust.

(5) In further research, the effects of particle size, ignition energy, initial turbulence, initial temperature, initial pressure on the explosion characteristic of the hybrid mixture of coal dust and gas will be taken into account, aiming to establish more accurate methods for predicting the explosion characteristic parameters.

Author Contributions: Y.W., W.J. and Y.Q. conceived and designed the experiments; Y.Q., L.L., X.G. and Z.L. performed the experiments and analyzed the data; and Y.W. and W.J. managed all the experimental and writing process as the corresponding authors. All authors discussed the results and commented on the manuscript. All authors have read and agreed to the published version of the manuscript.

Funding: This research was funded by the National Natural Science Foundation of China (51874120, 51904094, 51504083, 51674104, 51806056), China Postdoctoral Science Foundation(2020M672228), Basic Research Plan of Key Scientific Research Project of Henan University (20A620003); Science and Technology Research Project of Henan Province (202102310292); Program for Science \& Technology Innovation Talents in Universities of Henan Province (19HASTIT042), the Research Foundation for Youth Scholars of Higher Education of Henan Province (2017GGJS053), the Fundamental Research Funds for the Universities of Henan Province (NSFRF1606), Program for Innovative Research Team in University of Ministry of Education of China (IRT_16R22), Program for Innovative Research Team of Henan Polytechnic University (T2018-2), Foundation for Distinguished Young Scientists of Henan Polytechnic University (J2017-3).

Institutional Review Board Statement: Not applicable.

Informed Consent Statement: Not applicable.

Data Availability Statement: Data sharing not applicable.

Conflicts of Interest: The authors declare no conflict of interest.

\section{References}

1. Ji, W.T.; Yu, J.L.; Yu, X.Z. Explosion venting of hybrid mixtures: A comparison of standards NFPA 68 and EN 14491. J. Loss Prev. Process Ind. 2018, 54, 325-332. [CrossRef]

2. Bartknecht, W. Explosions: Course, Prevention, Protection; Springer Science \& Business Media: Berlin, Germany, 2012.

3. Song, S.X.; Cheng, Y.F.; Meng, X.R. Hybrid CH4/coal dust explosions in a 20-L spherical vessel. Process Saf. Environ. Prot. 2019, 122, 281-287. [CrossRef]

4. Kundu, S.K.; Zanganeh, J.; Eschebach, D. Explosion severity of methane-coal dust hybrid mixtures in a ducted spherical vessel. Powder Technol. 2018, 323, 95-102. [CrossRef]

5. Zhao, P.; Tan, X.; Schmidt, M. Minimum explosion concentration of coal dusts in air with small amount of $\mathrm{CH} 4 / \mathrm{H} 2 / \mathrm{CO}$ under 10-kJ ignition energy conditions. Fuel 2020, 260, 116401. [CrossRef]

6. Norman, F.; Berghmans, J.; Verplaetsen, F. The Dust Explosion Characteristics of Coal Dust in an Oxygen Enriched Atmosphere. Procedia Eng. 2012, 45, 399-402. [CrossRef] 
7. Pwael, K.; Roy, N.; Vijayshankar, A. Explosions of carbon black and propane hybrid mixtures. J. Loss Prev. Process Ind. 2013, $26,45-51$.

8. Cao, W.G.; Xu, S.; Liang, J.Y. Characteristics of flame propagation during coal dust cloud explosion. Explos. Shock Waves 2014, 34, 586-593.

9. Cao, W.G.; Huang, L.Y.; Zhang, J.X. Research on Characteristic Parameters of Coal-dust Explosion. Procedia Eng. 2012, 45, 442-447. [CrossRef]

10. Addai, E.K.; Clouthier, M.; Amyotte, P. Experimental investigation of limiting oxygen concentration of hybrid mixtures. J. Loss Prev. Process Ind. 2019, 57, 120-130. [CrossRef]

11. Mittal, M. Limiting oxygen concentration for coal dusts for explosion hazard analysis and safety. J. Loss Prev. Process Ind. 2013, 26, 1106-1112. [CrossRef]

12. He, C.Y. Study on the Explosion Risk under the Coexistence of Gas and Coal Dust. Saf. Coal Mine. 1996, 12, 22.

13. Bi, M.S.; Li, J.B. Flame propagation of methane-coal dust explosion in closed vessel. Meitan Xuebao 2010, 35, $1298-1302$.

14. Jing, G.X.; Liu, C.; Duan, X.W. Experimental study on gas-coal dust coupling explosion in semi-closed pipeline. Meitan Xuebao 2019, 44, 157-163.

15. Guo, C.W.; Shao, H.; Jiang, S.G. Effect of low-concentration coal dust on gas explosion propagation law. Powder Technol. 2020, 367, 243-252. [CrossRef]

16. Niu, Y.H.; Zhang, L.L.; Shi, B.M. Experimental study on the explosion-propagation law of coal dust with different moisture contents induced by methane explosion. Powder Technol. 2020, 361, 507-511. [CrossRef]

17. Cashdollar, K.L.; Hertzberg, M. 20L explosibility test chamber for dusts and gases. Rev. Sci. Instrum. 1985, 56, 596-602. [CrossRef]

18. Ji, W.T. Investigation on the Explosibility and Explosion Venting Characteristics of Hybrid Mixtures; Dalian University of Technology: Dalian, China, 2018.

19. Addai, E.K.; Gabel, D.; Krause, U. Lower explosion limit of hybrid mixtures of burnable gas and dust. J. Loss Prev. Process Ind. 2015, 36, 497-504. [CrossRef]

20. Khalili, I.; Dufaud, O.; Poupeau, M. Ignition sensitivity of gas-vapor/dust hybrid mixtures. Powder Technol. 2012, 217, 199-206. [CrossRef]

21. Sanchirico, R.; Russo, P.; Di, S.V. On the explosion and flammability behavior of mixtures of combustible dusts. Process Saf. Environ. Prot. 2015, 94, 410-419. [CrossRef]

22. EN14034-2006. Determination of Explosion Characteristics of Dust Clouds; European Committee for Standardisation (CEN): Brussels, Belgium, 2004.

23. Ji, W.T.; Xing, Q.Y.; Sun, H.L. Comparative analysis of the explosibility of several different hybrid mixtures. Powder Technol. 2018, 325, 42-48. [CrossRef]

24. Ji, W.T.; Yu, J.L.; Yu, X.Z. Experimental investigation into the vented hybrid mixture explosions of lycopodium dust and methane. J. Loss Prev. Process Ind. 2017, 51, 102-111. [CrossRef]

25. Dufaud, O.; Paula, P. CFD-DPM and experimental study of the dynamics of wheat starch powder/pyrolysis gases hybrid mixtures in the 20-L Sphere. Powder Technol. 2020, 372, 638-658.

26. Addai, E.K.; Ali, A.; Zaheer, A. Investigation of the explosion severity of multiphase hybrid mixtures. Process Saf. 2020, e12139. [CrossRef]

27. Song, L.; Zheng, T.L. Flammability and Explosion Risk of Post-explosion $\mathrm{CH}_{4}$ /air and $\mathrm{CH}_{4} /$ coal dust/air Mixtures. Combust. Sci. Technol. 2019. [CrossRef]

28. Sanchirico, R.; Benedetto, A.D.; Garcia-Agreda, A. Study of the severity of hybrid mixture explosions and comparison to pure dust-air and vapour-air explosions. J. Loss Prev. Process Ind. 2011, 24, 64-655. [CrossRef]

29. Garcia-Agreda, A.; Benedetto, A.D.; Russo, P. Dust/gas mixtures explosion regimes. Powder Technol. 2011, 205, 81-86. [CrossRef]

30. Bartknecht, W. Explosions; Springer: New York, NY, USA, 1981.

31. Ramalho, E.; Pinho, C. Explosibility of cork dust in methane/air mixtures. J. Loss Prev. Process Ind. 2006, 19, 17-23.

32. Denkevits, A. Explosibility of hydrogen-graphite dust hybrid mixtures. J. Loss Prev. Process Ind. 2007, 20, 698-707. [CrossRef]

33. Ajrash, M.J.; Zanganeh, J.; Moghtaderi, B. Effects of ignition energy on fire and explosion characteristics of dilute hybrid fuel in ventilation air methane. J. Loss Prev. Process Ind. 2016, 40, 207-216. [CrossRef]

34. Jiang, J.J.; Liu, Y.; Mashuga, C.V. Validation of a new formula for predicting the lower flammability limit of hybrid mixtures. J. Loss Prev. Process. Ind. 2015, 35, 52-58. [CrossRef] 